\title{
Experimental investigation and characterization of biodiesel production from leather industry fleshing wastes
}

\author{
Eshetu Getahun ${ }^{1,2, *}$, Nigus Gabiyye ${ }^{1,2}$ \\ ${ }^{1}$ Dept, Chemical Engineering, Bahir Dar, Ethiopia \\ ${ }^{2}$ Bahir Dar University, Institute of Technology, Bahir Dar, Ethiopia
}

Email address:

Eshetu_getahun@yahoo.com(E.Getahun),nigus_g@yahoo.com(N. Gabbiye)

\section{To cite this article:}

Eshetu Getahun, Nigus Gabiyye. Experimental Investigation and Characterization of Biodiesel Production from Leather Industry Fleshing Wastes. International Journal of Renewable and Sustainable Energy. Vol. 2, No. 3, 2013, pp. 120-129. doi: 10.11648/j.ijrse.20130203.17

\begin{abstract}
Production of biodiesel from industrial waste oil is becoming a primary candidate to overcome the problems associated with energy crisis and environmental pollution. In this study, low cost feed stocks leather industry fleshing waste was investigated experimentally for the production of biodiesel. The fleshing oil, which was investigated experimentally, had high acid value of $24.66 \mathrm{mgKOH} / \mathrm{g}$ and FFA level of $12.33 \%$. As a result, acid pretreatment followed by transestrifcation reaction path was chosen to produce biodiesel. Boric acid was used to reduce the lime of the flesh and sulfuric acid as catalyst and methanol as alcohol were used to reduce the FFA of the fleshing oil bellow $2.5 \%$ in the pretreatment reaction. After reducing the FFA of the fleshing oil bellow $2.5 \%$, transestrification reaction was conducted with alkaline catalyst potassium hydroxide. Several experiments were performed in a wide range of operating conditions to screen out the optimum operating parameters for the extraction of biodiesel from fleshing oil. The result demonstrated that $6: 1$ ration of methanol to oil, $1 \%$ of catalyst, temperature of $60^{\circ} \mathrm{c}$ and a contact time of $1 \mathrm{hr}$ are found to be the optimum operating parameters in the transesterification reaction. Over $97 \%$ conversion of the oil was achieved at the specified optimum operating conditions. Characterization the produced FAME reveals that viscosity of $4.47 \mathrm{~mm}^{2} / \mathrm{s}$, density of $876 \mathrm{~kg} / \mathrm{m}^{3}$, cetane number of 40.7 and iodine value of $61.3 \mathrm{gI}_{2} / 100 \mathrm{ml}$ were obtained. The fleshing oil biodiesel was compared with the international standards (ASTM and EN) and the result was in good agreement.
\end{abstract}

Keywords: Fleshing oil, Transestrification, Alkaline Catalyst, Pretreatment, Biodiesel

\section{Introduction}

Today, most of the energy used comes from fossil fuels: petroleum, coal, and natural gas. The scarcity of conventional fossil fuels, growing emissions of combustion generated pollutants, and their increasing costs will make biomass sources more attractive in the recent years to substitute the conventional fuel [1]. One of these biomass sources would be the leather industry fleshing wastes.

Leather industry plays a major role by creating job opportunity for the employees at country wide. It also accommodates large number of human labors in developing countries like Ethiopia. The countries economy, growth and development can be facilitated by investing large amount of money in the manufacturing sector. One of the manufacturing sectors is the leather industries. Ethiopia is relatively well endowed in its livestock base in the continent with a share of 12,15 and 22 percent of the world cattle, sheep and goats population respectively [2-3]. This indicates that, the country is one of the most promising leather producing country in Africa. Currently there are 20 tanneries, which are operational in this sector employing about 6000 workers. The Ethiopian government invest large amount of money in the manufacturing sectors such as leather industries and it is the leading exporter and accounting for about $67 \%$ of the total manufactured exports [4]. Although the leather industry is the prominent one in the world leather trade, it has also a negative environmental impact. The leather industry is highly environment polluting sectors by generating organic and inorganic pollutants. The wastes generated can be solid or liquid wastes that pose a major challenge to the environment and the ecosystem [4]. The solid wastes that are generated in the leather industries are originated from the pre-tanning 
stages. These wastes are mainly originated from pre-fleshing, fleshing, shaving and trimming. These solid wastes have high amount of fat contents for the production of bio-energy such as biodiesel. As shown in table1.1, fleshing wastes has considerable fatty acid composition when compared to the other vegetable oil fatty acid composition. However, these wastes are not changed in to value added products. One way to recover the leather industry wastes is using them as feedstock in biodiesel production due to their rich fat content [5]. Consequently, the pollution coming from the leather industry wastes can be reduced dramatically and more value added products can be obtained by converting them to biodiesel.

The advantages of biodiesel over diesel fuel are its renewability, higher combustion efficiency, lower sulphur and aromatic content, higher cetane number, higher biodegradability, better emission profile, safer handling. Besides the superb lubricating property of biodiesel and its similarities in physicochemical properties to diesel, makes it an excellent fuel for compression ignition engines [6]. Currently, the usage of oil directly from the agricultural industry has the greatest potential source for the production of biodiesel. However, producing biodiesel from virgin oil is not commercially feasible to satisfy the need of the transportation sector since the raw oil is too pricy [7]. Moreover, the cost of converting raw oil from agricultural sources can be too expensive to compete with fossil diesel. On the other side, there are potential sources in oil and leather industry wastes for the production of biodiesel. Producing biodiesel from this waste has a dual purpose. In one hand, it reduces environment load by reducing global warming and finally these wastes are changed into value added products. However, these wastes often contain significant amounts of free fatty acid (FFA) which need further treatment to lower the free fatty acid because FFAs cannot be converted to biodiesel using alkaline catalysts. FFAs react with an alkaline catalyst and thus soaps are produced by this reaction. Soaps prevent the separation of the ester, glycerin and wash water [5]. Biodiesel is produced by trans esterification of oils and fats with short-chain alcohols or by the esterification of fatty acids [8].The transesterification reaction consists of transforming triglycerides into fatty acid alkyl esters, in the presence of an alcohol, such as methanol or ethanol, and a catalyst, such as an alkali or acid, with glycerol as a by-product. It has been investigated that the process of transesterification is mainly affected by the mode of reaction condition, molar ratio of alcohol to oil, type and amount of catalysts, reaction time, FFA content and temperature [5, 8]. Base- or alkali-catalyzed reactions typically using sodium hydroxide or potassium hydroxide are most common when the oils are neutral or mostly free of fatty acids [9]. Acid catalysts using hydrochloric or sulfuric acid typically result in substantially reduced trans esterification rates by as much as 4000 times less than homogeneous base-catalyzed reactions and require higher reaction temperatures of nearly $100^{\circ} \mathrm{C}[10]$. However, acid catalysts can be very effective in driving the transesterification process when oils contain large amounts of free fatty acids as in the case of some yellow and brown grease that are by-products of the food and animal rendering industries. With excessive free fatty acids present, acid pretreatment followed by transestrification reaction path is the best option.

Different researchers have investigated the potential of animal fats and waste oils for biodiesel production [5]. To the best of our knowledge, very limited researchers have worked on the fleshing oil especially with high FFA. Colak et al. $[5,11]$ used the fat released from pre-fleshings of sheep skins by boiling with water under high speed grinding. Because the FFA value of the fleshing oil was about $1.2 \%$, they did not perform a pretreatment reaction for the fleshing oil. They used methanol and KOMe $(30 \%$ in methanol) for transesterification and obtained high ester yield up-to 95\%. Kolomaznik et al. [5, 12] evaluated the leather industry tannery wastes for biodiesel production. The acid value of waste tannery fat was $10.6 \mathrm{mg} \mathrm{KOH} / \mathrm{g}$. They carried out the transesterification of the waste tannery fat with only $\mathrm{KOH}$ and methanol. However, the conversion to methyl ester was about $40 \%$ which was considerably low due to high FFA content of the fat. Therefore, they preferred tetramethylammonium hydroxide for esterification of FFA and obtained better results.

Isler et al. [5, 13] produced biodiesel from leather industry waste fleshing fats. The acid value of the fat was $0.28 \mathrm{mg} \mathrm{KOH} / \mathrm{g}$. Therefore, the fleshing fat was converted to biodiesel via transesterification. They used $\mathrm{NaOH}$ and methanol for determining optimum transesterification conditions to produce biodiesel. The fuel properties of the fleshing oil biodiesel fit the EN 14214 biodiesel standard specifications except for cold plugging filter point and oxidation stability. Alptekin.E.et.al [5] produced biodiesel from leather industry waste fleshing fats with a conversion of $95.5 \%$ and analyzed the pretreatment stage and still it was below the standard. Moreover, none of the researchers focus on the fleshing oil extraction mechanism and treatment of the flesh which has high amount of lime and other chemical that depress the biodiesel production and also bring environmental pollution. Therefore, the purpose of the present study is to investigate low cost feed stock such as fleshing oil for biodiesel production through performing extensive experiments on the oil extraction and production of biodiesel in order to obtain high quality of biodiesel from fleshing oils. 
Table 1. Fatty acid distribution of animal and vegetable oil sources [10]

\begin{tabular}{|c|c|c|c|c|c|c|}
\hline Source & Palmitic 16:0 & Palmitoleic16:1 & Stearic 18:0 & Oleic 18:1 & Linolic 18:2 & Linolenic18:3 \\
\hline Rape oil & 3.5 & - & 0.9 & 64.4 & 22.3 & 8.2 \\
\hline Olive oil & 9.2 & 0.8 & 3.4 & 80.4 & 4.5 & 0.6 \\
\hline Sunflower & 6.0 & - & 4.2 & 18.7 & 69.3 & - \\
\hline Soybean oil & 10.6 & - & 4.8 & 22.5 & 52.3 & 8.2 \\
\hline Palm oil & 47.9 & - & - & 4.2 & 37 & 9.1 \\
\hline Cottonseed oil & 28.7 & - & 0.9 & 13 & 57.4 & - \\
\hline Poppy seed oil & 12.6 & 0.1 & 4.0 & 22.3 & 60.2 & 0.5 \\
\hline Sesame seed oil & 13.1 & - & 3.9 & 52.8 & 30.2 & - \\
\hline Corn oil & 11.8 & - & 2.0 & 24.8 & 61.3 & - \\
\hline Castor oil & 1.1 & - & 3.1 & 4.9 & 1.3 & - \\
\hline Jatropha curcas & 13.3 & 1.0 & 4.9 & 32.0 & 45 & 0.2 \\
\hline Lard & 17.3 & 1.9 & 15.6 & 42.3 & 19.3 & 1.0 \\
\hline Tallow & 28.4 & - & 14.8 & 44.6 & 9.2 & 0.4 \\
\hline Fleshing oil & 27.25 & 5.10 & 13.23 & 42.06 & 2.04 & 0.16 \\
\hline Yellow grease & 23.2 & 3.8 & 13.0 & 44.3 & 7.0 & 0.7 \\
\hline Brown grease & 22.8 & 3.1 & 12.5 & 42.4 & 12.1 & 0.8 \\
\hline White grease & 23.3 & 3.5 & 11.0 & 47.1 & 11.0 & 1.0 \\
\hline
\end{tabular}

\section{Materials and Methods}

\subsection{Materials and Chemicals}

Enough amounts of goat and sheep fleshing fat waste were collected from Bahir Dar leather factory located in Bahir Dar, Ethiopia as main raw materials. Moisture content of flesh was $60 \%$. The flesh waste was washed with distilled water so as to remove the impurities.

All chemicals used in this study were analytical grades; Analytical grade methanol (99\%), obtained from bulk liquid fuels distributors was used for the reaction, $\mathrm{KOH}$ $(92 \%)$ as catalyst, Toluene (99\%), Phenolphthalein, diethyl-ether, sulfuric acid, ethanol, iodine, bromine liquid, sodium thiosulphate, boric acid and hydrochloric acid were used for raw material treatment and biodiesel characterization.

\subsection{Experimental Setup and Descriptions}

Simple extractive boiler equipped with heating stove was used to extract the oil from the flesh (fig.2.1a). To this end, a weighed amount of flesh waste was charged into the extractive boiler. The mixture was agitated and heated to the desired temperature of $95^{\circ} \mathrm{C}$. Then, the mixture was centrifuged with centrifuge model TD3, rpm 4000 to separate the oil from the mixture. Finally the fleshing oil was washed several times with distilled water and dried to keep it in moisture free container.

All the pretreatment and transestrification experiments were performed in a laboratory scale glass reactor shown in fig.2.1b. The reaction flask was equipped with reflux condenser, magnetic stirrer, chiller and thermometer. Hot plate magnetic stirrer was used to heat and agitate the reaction mixture. When the reaction temperature is reached $60^{\circ} \mathrm{C}$, a defined amount of catalyst previously dissolved in methanol was added to the heated oil. The mixture was stirred with magnetic stirrer for $1 \mathrm{~h}$. After cooling the reactor system, the reaction mixture was centrifuged with centrifuge model TD3, rpm 4000 to separate the estrified fatty acid and alcohol- water- acid mixture. The estrified fatty acid was further heated to $105^{\circ} \mathrm{C}$ to remove any remaining water. The acid and FFA values of the fat-ester mixture were determined and recorded. After obtaining the desired FFA level, the transestrification reaction experiment was performed in the same reactor. Vacuum Filter was used for separation of the oils and the biodiesel from impurities.

\subsection{Experiments}

\subsubsection{Flesh Waste Treatment and Oil Extraction}

It was reported that the tannery fleshing wastes had high amount of limes and these lime should be first neutralized with boric acid [11]. To this end the flesh was subjected a two stage water washing in a paddle to wash out the alkalis. Then, about $0.5-1 \%(\mathrm{w} / \mathrm{w})$ acid was added with sufficient water in order to neutralize the $\mathrm{pH}$. The flesh was soaked with the acid for an hour at atmospheric condition. Then, the flesh was chopped into small size and the oil was extracted by boiling at a temperature of $95^{\circ} \mathrm{C}$ as shown in fig2.1a. Finally, the oil was filtered using centrifuge and vacuum filter. The yield of the fleshing oil was calculated:

Yield $(\%)=\frac{\text { Dry mass of flesh }- \text { Dry mass of sludge }}{\text { Dry mass of flesh }} \times 100 \%$

The water content, $\mathrm{pH}$, acid value, density and viscosity of the extracted oil were determined prior to pretreatment of the fleshing oil. Then, titration was conducted to determine the amount of FFA of the resulted oil. This allows us to choose the best route for production of biodiesel from fleshing leather wastes. i.e whether acid or base-catalyzed or a combination of processes will be used. The acid value was 
expressed as mg KOH per $\mathrm{g}$ of oil and the free fatty acid was expressed as half of the acid value.

$$
\text { Acid value }(\mathrm{AV})=\frac{V \times N \times M w_{K O H}}{W}
$$

Where, V-titrant volume, N-concentration of titrant, $\mathrm{MW}_{\mathrm{KOH}}$-molecular weight of $\mathrm{KOH}$ and $\mathrm{W}$-sample weight of the oil.

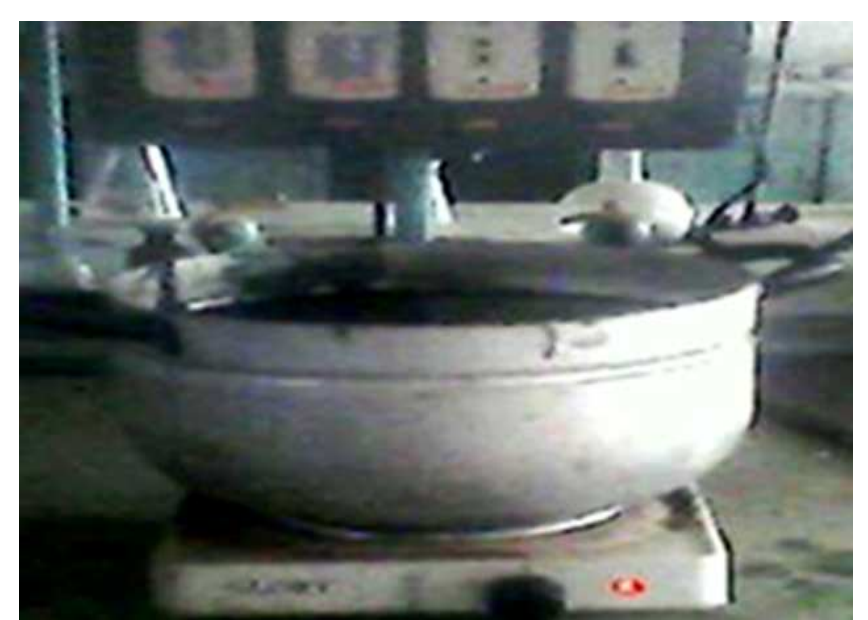

(a)Fleshing oil extraction

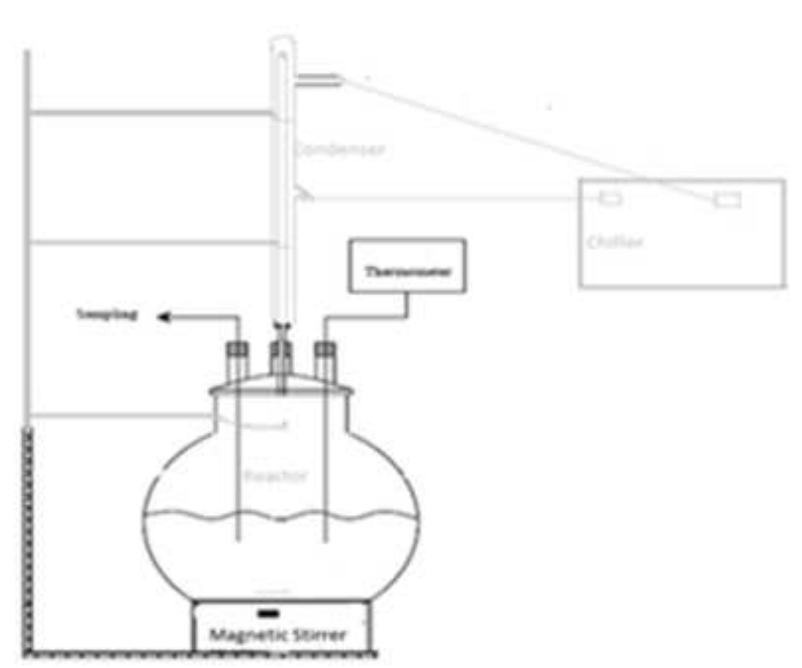

(b)Esterification and transestrification reaction

Figure 1. Experimental set up for biodiesel production

\subsubsection{Etherification and Transestrification}

Sulfuric acid was used for the pretreatment of the fleshing oil as a catalyst. The esterification reaction was performed for wide range of sulfuric acid percentage concentration $(1 \%$, $3 \%, 5 \%, 10 \%$, and $15 \%$ ) and alcohol molar ratio of $30: 1$ based on the acid value of the fleshing oil to reduce the FFA below $2.5 \%$ in one hour contact time at a temperature of $60^{\circ} \mathrm{C}$.

$$
\mathrm{RCOOH}+\cdot \mathrm{R}^{\prime} \mathrm{OH} \stackrel{\text { Acid catalyst, }}{\longrightarrow} \cdot \mathrm{RCOOR}{ }^{\prime}+\cdot \mathrm{H}_{2} \mathrm{O}
$$

The transesterification reaction took place when the estrified oil was mixed with the alkoxide (alcohol-catalyst $\mathrm{mix})$. The general transesterification reaction for acid or base-catalyzed conversion of oils consisting primarily of neutral triacylglycerols (TAG) in reaction with alcohols to form alkyl esters as presented in fig. 2.2. As it can be seen in the figure, the stoichiometric molar ratio of alcohol to triglyceride is $3: 1$; but since the transesterification is a reversible reaction and excess amount of alcohol is commonly used in order to shift the equilibrium in benefit of alkyl ester formation. The transesterification reaction of TAGs takes place in three steps where TAG is first converted to a diacylglycerol (DAG) and one fatty acid ester. Then the DAG is converted to monoacylglycerol (MAG) liberating an additional fatty acid ester, and finally the MAG is converted to glycerol liberating the final fatty acid ester.

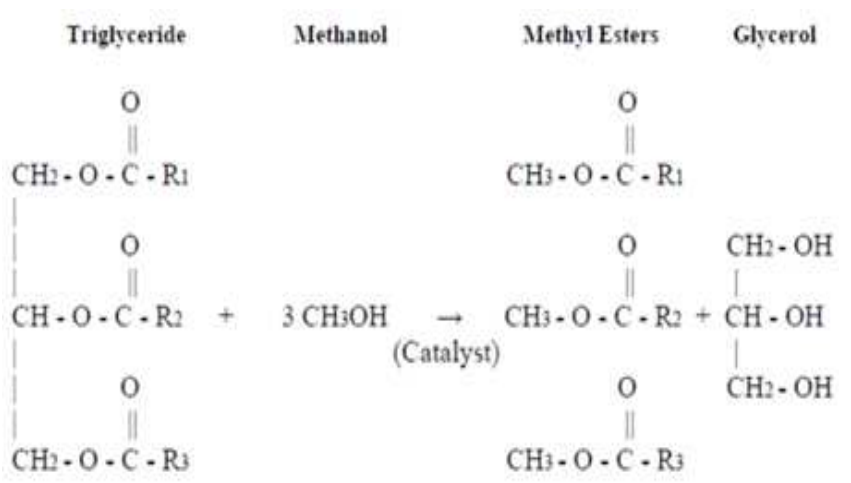

Figure 2. General transestrification reaction

$\mathrm{KOH}$ and methanol were used as catalyst and reactant respectively. The transestrification reaction was conducted for methanol oil ratio of $4: 1$ and $6: 1$, catalyst mass of $1 \%$ and $1.5 \%(\mathrm{w} / \mathrm{w})$ in the temperature range of $45-60^{\circ} \mathrm{C}$ at contact time of one hour. After the transestrification reaction was accomplished, the glycerol phase formed in the bottom layer was removed by decantation. The biodiesel was washed with hot distilled water, then with 35 $\mathrm{ml}$ of hydrochloric acid $0.5 \%$ to neutralize the remaining catalyst and to decompose the soaps formed during the transesterification reaction. The methyl ester (biodiesel) was washed with warm water and heated for about $110^{\circ} \mathrm{C}$ to separate the excess methanol and water. The final product was weighed for determination of product yield and then characterized. The yield of biodiesel (FAME) was estimate by taking the ratio of total methyl ester produced and the initial amount of flesh oil used. It was reported by Schinas et al. [12] that the minimum biodiesel yield should be $97.5 \%$ after transesterification reaction. Therefore, the yield of transesterification reaction was calculated as:

$$
\text { Yisld }(W)=\frac{\text { Total weight of methyl eiter }}{\text { Total weight of ail in the sample. }} \times 100 \%
$$

Finally, the produced methyl ester physicochemical 
property was characterized using international standard testing methods such as ASTM and EN.

\subsection{Biodiesel Characterization}

Density (ASTM D4052-91): The biodiesel sample at a known temperature $\left(25^{\circ} \mathrm{C}\right)$ was filled into graduated cylinder $(50 \mathrm{ml})$. Hydrometer was used to measure the specific gravity of the fuels specified at $25^{\circ} \mathrm{C}$ according to ASTM D5002-94.

Viscosity at $40^{\circ} \mathrm{C}$ (ASTM D 445): Viscometer (SV5) was used to measure the dynamic viscosity of the samples at $40^{\circ} \mathrm{C}$. The kinematic viscosity was calculated from the given data using,

$$
\eta=\frac{\mu}{\rho}
$$

Where, $\eta$ is kinematic viscosity $\left(\mathrm{mm}^{2} / \mathrm{s}\right), \mu$ is dynamic viscosity (Pa.s), and $\rho$ is density $\left(\mathrm{kg} / \mathrm{m}^{3}\right)$.

Saponification Value (AOCS CD3 1993): The saponification value (SV) of the obtained biodiesel was determined via dissolving $30 \mathrm{~g}$ of $\mathrm{KOH}$ pellets in one litter of ethanol to prepare $0.5 \mathrm{~N} \mathrm{KOH}$. Then, 1 gram of biodiesel sample was weighted and added into $25 \mathrm{ml} \mathrm{KOH}$ solution with $0.5 \mathrm{~N}$ molar concentration. $4 \mathrm{ml}$ of ethanolether solvent $(100 \mathrm{ml}$ ethanol $+100 \mathrm{ml}$ ether) was added to the mixture and then refluxed for 30 minute in a hot plate magnetic stirrer. After cooling, a few drop of phenophethaline was added and titrated by $0.5 \mathrm{~N} \mathrm{HCl}$ acid (volume Va) solution until the faint pink color permanently disappeared. And a blank determination was carried out upon the same quantity of potassium hydroxide solution at the same time and under the same conditions (volume $\mathrm{Vb}$ ). The final result was calculated as below:

$$
\mathrm{SV}=56.1 \frac{N \times\left(V_{a}-V_{b}\right)}{W}
$$

Where, $\mathrm{W}=$ weight of oil or biodiesel $(\mathrm{g})$

$\mathrm{Va}=$ Volume $(\mathrm{ml})$ of hydrochloric acid used in test $\mathrm{Vb}=$ Volume $(\mathrm{ml})$ of hydrochloric acid used in blank

$\mathrm{N}=$ Normality of hydrochloric acid

Iodine value (IV) [13]: The iodine value determination was done by measuring one gram of biodiesel/oil and dissolving it in $10 \mathrm{ml}$ of chloroform. $25 \mathrm{ml}$ of hanus solution (which was prepared by dissolving $13.6 \mathrm{~g}$ of iodine in $400 \mathrm{ml}$ glacial acitic acid by adding $6 \mathrm{ml}$ of bromine liquid) and allowed it in dark place for $30 \mathrm{~min}$. $10 \mathrm{ml}$ of $15 \% \mathrm{KI}$ $(15 \mathrm{~g}$ of KI dissolved in $100 \mathrm{ml})$ added. The solution was titrated against $0.1 \mathrm{~N}$ sodium thiosulphate until yellow solution turns in to almost colorless.

$$
\mathrm{IV}=\frac{M_{1} \times\left(V_{b}-V_{t}\right)}{\mathrm{M}_{\mathrm{a}}}
$$

Where, IV = Iodine value $\left(\mathrm{g}\right.$ I2 / $100 \mathrm{~g}$ amostra), $\mathrm{V}_{\mathrm{t}}=$ volume of sodium thiosulphate solution for the sample $(\mathrm{mL}), \mathrm{Vb}=$ volume of sodium thiosulphate solution for the blank $(\mathrm{mL}), \mathrm{C}_{\mathrm{t}}=$ standard sodium thiosulphate solution concentration $(\mathrm{N})$;

$\mathrm{M}_{\mathrm{a}}=$ mass of the biodiesel sample

$(\mathrm{g}), \mathrm{M}_{\mathrm{I}}=$ molar mass of iodine.

Higher Heating value (HHV): Determination of HHV was conducted using empirical equations available. The increase in the iodine value (IV) (i.e., carbon-carbon double bond, $-\mathrm{C}=\mathrm{C}-$, content) results in a decrease in the heat content of an oil. Therefore, for calculation of the HHVs $(\mathrm{MJ} / \mathrm{kg})$ of oils, the following equation was suggested [14].

$$
\mathrm{HHV}=49.43-\left[\frac{(0.041 \times S V)+0.015 \times I V}{\mathrm{M}_{\mathrm{a}}}\right]
$$

Cetane Number (CN) (ASTM D613): Cetane number determination was done using empirical formula developed by kalayasiri [15]. The calculation was based on the results from Saponification number (SN) and Iodine value (IV) of oils. The $\mathrm{CN}$ was calculated as below,

$$
\mathrm{CN}=46.3+\left(\frac{5458}{\mathrm{SN}}\right)-0.225 \times \mathrm{IV}
$$

\section{Results and Discussions}

\subsection{Treatment of the Flesh and Oil Extraction}

The flesh waste was treated with boric acid to remove the alkali solution before extraction was commenced. The physical and chemical properties of the extracted fleshing oil including the iodine value, acid value, density, kinematic viscosity and $\mathrm{pH}$ is presented in table3.1. The pretreatment result reveals that the tannery fleshing waste has high amount of alkali solution which has a $\mathrm{pH}$ of 11.8 . After treating the flesh with boric acid the $\mathrm{pH}$ was reduced to 8 . The yield of the fleshing oil was determined to be $64 \%$. Most importantly, the fleshing oil which was extracted from goat skin flesh was liquid at room temperature while the fleshing oil that was obtained from sheep skin flesh was solid at room temperature as it can be observed in fig3.1a and $b$. This suggests that the degree of saturation of the oil depend on the raw material type. It is also observed that the color of saturated oil was white while the unsaturated oil was red.

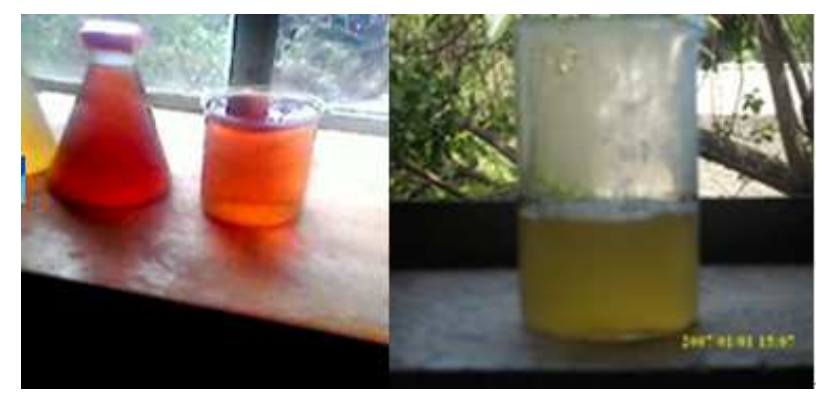

(a)Goat flesh oil (b) Sheep flesh oil

Figure3. Oil extracted from fleshing wastes 
Based on the oxidative stability, saturated fleshing oils are more stable for oxidation than unsaturated fleshing oil [16]. Due to that, this study was focused on the saturated fleshing oil.

The extracted fleshing oil was subjected to titration to determine the FFA contents. The experimental result demonstrated that the fleshing oil has a FFA content of $12.33 \%$. It was reported that used cooking oils typically contain $2-7 \%$ FFA, and animal fats contain 5-30\% FFA [16] suggesting that the obtained fleshing oil is in the range of literature values. It was reported elsewhere [17] that pretreatment is mandatory when FFA of the oil is above $2.5 \%$. This is because the high level of FFA enhances the saponification reaction by depressing the biodiesel reaction route.

Table 2. Major results of properties of the fleshing and pretreated fleshing oil

\begin{tabular}{llll}
\hline Property & Unit & Fleshing oil (Before Treatment) & Fleshing oil (Aftertreatment) \\
\hline Density@25 $5^{\circ} \mathrm{c}$ & $\mathrm{Kg} / \mathrm{m}^{3}$ & 904 & 900 \\
Kinematic viscosity@ $40^{\circ} \mathrm{c}$ & $\mathrm{mm}^{2} / \mathrm{s}$ & 40.20 & 27.65 \\
Acid value & $\mathrm{mg} \mathrm{KOH} / \mathrm{g}$ & 24.66 & 3.14 \\
Saponification value & $\mathrm{mg} \mathrm{KOH} / \mathrm{g}$ & 198.63 & 185.2 \\
Higher heating value & $\mathrm{MJ} / \mathrm{kg}$ & 40.20 & 40.86 \\
Iodine value & $\mathrm{g} / 100 \mathrm{~g}$ & 73.96 & 65 \\
Water content & $\%$ mass & 0.31 & 0.31 \\
FFA & $\%$ & 12.33 & 1.5 \\
$\mathrm{PH}$ & - & 11.8 & 8.0 \\
Titrant volume $(\mathrm{KOH})$ & $\mathrm{ml}$ & 4 & 6 \\
Amount of Catalyst & $\mathrm{gm}$ & 14 & - \\
Yield of fleshing oil & $\%$ & 64 & - \\
\hline
\end{tabular}

\subsection{Estrification Reaction}

The esterification reaction was conducted at $60^{\circ} \mathrm{C}$ for $1 \mathrm{~h}$ contact time. Sulfuric acid was used to initiate the esterification reaction. The result is presented in fig.3.2. As it can be seen in Fig.3.2, the acid values of the fleshing oil were decreased with increasing the amount of sulfuric acid. The FFA value was determined as half of the acid value of the fleshing oils. It can be seen in fig. 3.2 only $10 \%$ of sulfuric acid is needed to lower the FFA to the required level $(2.5 \%)$.The physic-chemical properties of the treated oil is presented in Table 3.1 and compared with untreated oil. As it can be seen in table3.1, the kinematic viscosity, density and acid values of the fleshing oil were reduced appreciably in the pretreatment experiment due to partial oil conversion which can be also greatly reduced in the transestrification reaction for the wellbeing of the engine performance.

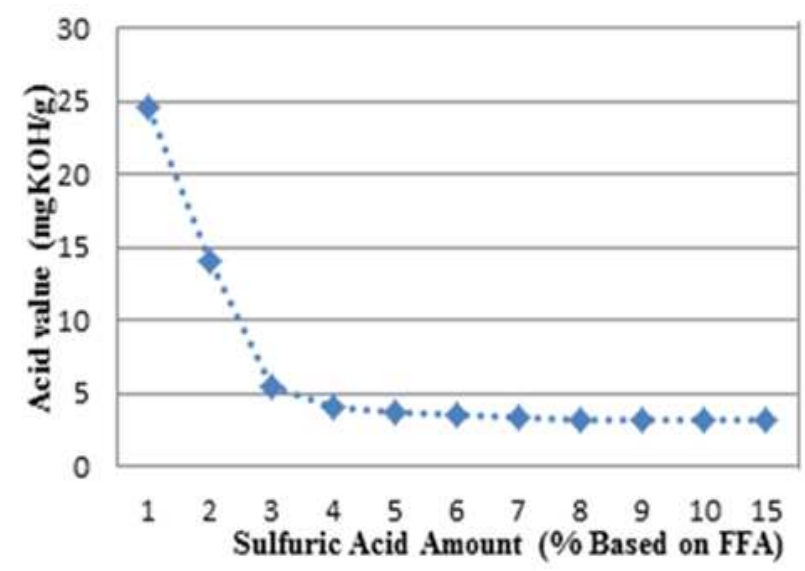

Figure 4. Effect of catalyst on the acid value of pretreated fleshing oil

\subsection{Effect of Operating Condition on Transestrification}

Several investigators reported that the yield and separation of biodiesel from glycerol depends on the type of alcohol used during transestrification reaction [18]. Utilization of methanol rather than ethanol in the transestrification reaction enhances glycerol and biodiesel separation easily. The product of the reaction mixture is presented in fig. 3.3. As it can be seen in fig3.3, biodiesel and glycerol did form two distinct layers where the upper part was biodiesel and the bottom layer was the glycerol. Following the procedure specified in section 2.3.2, the biodiesel was separated by decantation and purified by washing several times with warm water. The calculated yield and the physicochemical properties were displayed in table 3.2 .

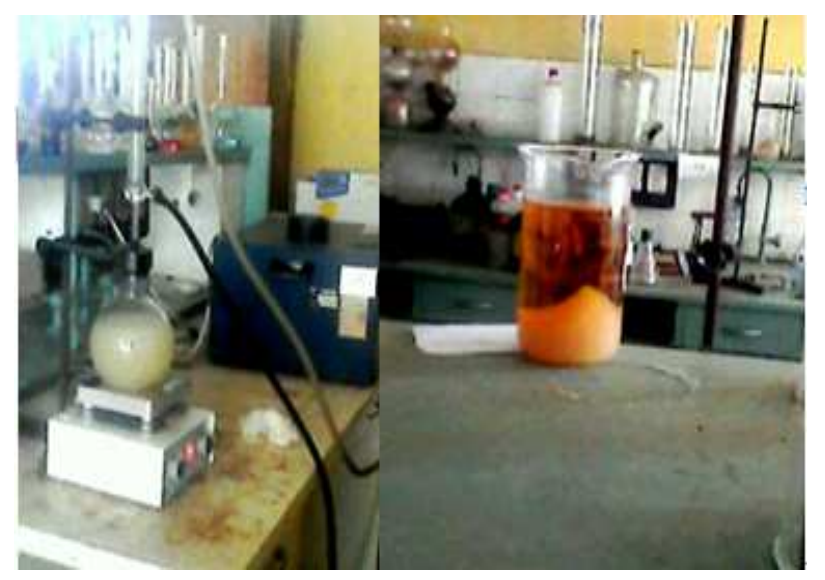

Figure 5. Transestrification reaction and biodiesel layer

The yield of biodiesel was determined at optimum operating condition of the reaction. The fleshing oil methyl 
ester yield is presented as function of catalyst mass in fig.3.4. As it can be seen in fig.3.4, an increase in the mass of catalyst from 0.5 to $2 \mathrm{KOH} / \mathrm{Oil}$ (w/w) leads a considerable decrease of biodiesel yield. This could be due the initiation of saponification reaction at high excess of potassium salt which competitively consumes the oil [12]. It was also absorbed that increasing methanol ratio leads an important increase in biodiesel yield. In this particular work conversion of $97.1 \%$ was obtained from the transestrification reaction at the optimum methanol ratio of $6: 1$, temperature of $60^{\circ} \mathrm{C}$, catalyst concentration of $1 \%$ and rpm of 750 .



Figure 6. Effect of catalyst mass on biodiesel yield

\subsection{Physicochemical Characteristics of the Biodiesel}

Iodine value (IV) is an important parameter for determination of the overall degree of saturation of the oil. The value of iodine number determines viscosity, cloud point, and reactivity characteristics of the fuel. As it can be observed in table 3.2, the iodine value of the produced biodiesel was in the range of $62-73$ gram of $\mathrm{I}_{2} / 100 \mathrm{ml}$ of oil. It was reported that the maximum iodine value of biodiesel is 120[19]. This suggests that the quality of biodiesel produced in this work is in good agreement with the other literature results. High degrees of unsaturation are generally not desirable for fuels. This is due to the fact that their oxidation reactions generally found at high temperatures during combustion which may result in formation of irreversible polymerized condensation products.

The density of biodiesel was determined via hydrometer. The result obtained at different methanol-oil ratio is presented in fig3.5 as a function of catalyst mass. It was observed in this study that the density of biodiesel decreased by increasing methanol ratio and catalyst amount as shown in fig.3.5. The fleshing oil density decreased from 904 to $876.88 \mathrm{Kg} / \mathrm{m}^{3}$ through transestrification reaction.

In this study, the viscosities of the biodiesel that was produced at lower temperature and lower catalyst amount were higher than that of the corresponding experiments conducted at higher temperature with the same feed ratio. But at higher temperature and higher amount of catalyst, the viscosities could be lower because as the temperature increase, the transestrification reaction was facilitated and hence resulting in a decrement of viscosity as shown in Fg.3.6. The average value of the biodiesel viscosity in this experiment was $3.88 \mathrm{~mm}^{2} / \mathrm{sec}$ at $40^{\circ} \mathrm{c}$ and $750 \mathrm{rpm}$.



Figure 7. Effect of catalyst mass on viscosity

Higher Heating Value (HHV) of the biodiesel produced in this study was $40.73 \mathrm{MJ} / \mathrm{kg}$. Extensive literatures reported that the HHVs of biodiesels (39 to $41 \mathrm{MJ} / \mathrm{kg}$ ) are slightly lower than those of gasoline $(46 \mathrm{MJ} / \mathrm{kg}$ ), petro diesel (43 $\mathrm{MJ} / \mathrm{kg}$ ), or petroleum (42 MJ/kg) [20]. The general physicochemical properties of the fleshing oil biodiesel are displayed in Table 3.2. As it can be seen in table3.2, HHV and cetane number value did not show a significant change for different operating conditions in this study. As the temperature increased, density and viscosity also decreased due to high conversion of the oil.

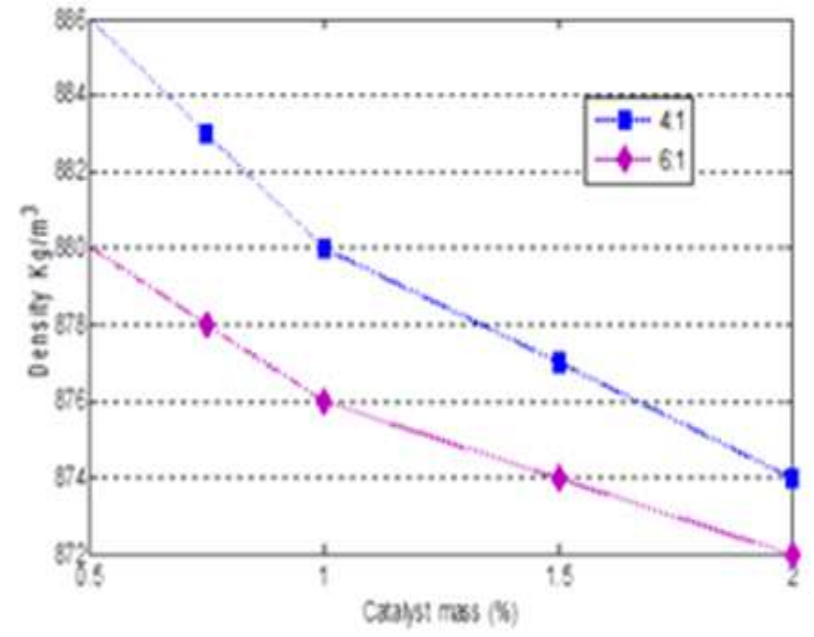

Figure 8. Effect of catalyst mass on density 
Table 3. Fuel properties of biodiesel at different operating condition

\begin{tabular}{|c|c|c|c|c|c|c|c|c|c|c|}
\hline Run & $\begin{array}{l}\text { Ratio of } \\
\text { Methanol : } \\
\text { fleshing oil }\end{array}$ & $\begin{array}{l}\text { Operating } \\
\text { temperatur } \\
\left.\text { e ( }{ }^{\circ} \mathrm{c}\right)\end{array}$ & $\begin{array}{l}\text { Catalyst } \\
\text { (\%wt.of oil) }\end{array}$ & $\begin{array}{l}\text { Density } \\
\left(\mathrm{kg} / \mathrm{m}^{3}\right)\end{array}$ & $\begin{array}{l}\text { Kinematic } \\
\text { Viscosity } \\
\left(\mathrm{mm}^{2} / \mathrm{s}\right)\end{array}$ & $\begin{array}{l}\text { HHV, } \\
\text { MJ/Kg }\end{array}$ & $\begin{array}{l}\mathrm{AV}, \\
\mathrm{mgKOH} / \mathrm{m} \\
\mathrm{g}\end{array}$ & $\mathrm{CN}$ & $\begin{array}{l}\text { IV } \\
\text { (gI2/100 } \\
\mathrm{ml}\end{array}$ & $\begin{array}{l}\text { FAME } \\
\text { Yield (\%) }\end{array}$ \\
\hline 1 & $4: 1$ & 45 & 1 & 880.4 & 5.18 & 40.54 & 0.35 & 60.46 & 62.03 & 93.6 \\
\hline 2 & $4: 1$ & 60 & 1 & 878.2 & 4.55 & 40.94 & 0.45 & 63.52 & 52.5 & 96.0 \\
\hline 3 & $4: 1$ & 45 & 1.5 & 875.5 & 3.42 & 41.02 & 0.61 & 63.25 & 56.06 & 92.0 \\
\hline 4 & $4: 1$ & 60 & 1.5 & 874.1 & 3.2 & 40.63 & 0.52 & 58.95 & 72.76 & 93.4 \\
\hline 5 & $6: 1$ & 45 & 1 & 878.3 & 3.98 & 40.37 & 0.23 & 58.23 & 71.57 & 85.5 \\
\hline 6 & $6: 1$ & 60 & 1 & 877.6 & 3.53 & 40.79 & 0.42 & 61.57 & 60.8 & 97.3 \\
\hline 7 & $6: 1$ & 45 & 1.5 & 876.7 & 3.43 & 41.01 & 0.29 & 62.63 & 59.64 & 93.2 \\
\hline 8 & $6: 1$ & 60 & 1.5 & 874.9 & 3.31 & 40.8 & 0.50 & 62.01 & 58.45 & 94.1 \\
\hline 9 & $4: 1$ & 45 & 1 & 881.0 & 4.14 & 40.54 & 0.54 & 60.65 & 60.8 & 94.6 \\
\hline 10 & $4: 1$ & 60 & 1 & 877.9 & 3.91 & 41.08 & 0.40 & 63.70 & 54.87 & 97.0 \\
\hline 11 & $4: 1$ & 45 & 1.5 & 875.2 & 3.54 & 40.54 & 0.30 & 61.29 & 57.26 & 94.1 \\
\hline 12 & $4: 1$ & 60 & 1.5 & 874.9 & 3.26 & 40.65 & 0.72 & 60.87 & 62.03 & 82.7 \\
\hline 13 & $6: 1$ & 45 & 1 & 877.8 & 4.67 & 40.53 & 0.22 & 58.99 & 70.37 & 90.8 \\
\hline 14 & $6: 1$ & 60 & 1 & 876.9 & 4.47 & 40.77 & 0.65 & 61.30 & 62.02 & 97.1 \\
\hline 15 & $6: 1$ & 45 & 1.5 & 877.0 & 3.81 & 40.86 & 0.37 & 61.64 & 62.03 & 90.6 \\
\hline 16 & $6: 1$ & 60 & 1.5 & 873.8 & 3.62 & 40.63 & 0.67 & 60.97 & 60.84 & 92.7 \\
\hline $17 *$ & $5: 1$ & 52.5 & 1.25 & 876.88 & 3.88 & 40.73 & 0.45 & 61.25 & 62.102 & 92.84 \\
\hline
\end{tabular}

Where $17 *$ is the average value

The $\mathrm{CN}$ relates to the ignition delay time of a fuel upon injection into the combustion chamber. It is a measure of ignition quality of diesel fuels; a high $\mathrm{CN}$ implies short ignition delay. The average cetane number is found to be 61.25. It was also reported in the international standards that the $\mathrm{CN}$ of biodiesel is in the ranges of 48-65 and animal fat biodiesel has high cetane number than the vegetable oil biodiesel [21].

Effect of Temperature on viscosity: Fig3.7 presents the effect of temperature on viscosity. As the temperature Increase in the transestrification reaction, conversion rate of the oil also increase. As it can be seen, the viscosity dramatically decreased with increasing temperature and the optimum kinematic viscosity of biodiesel at $40^{\circ} \mathrm{C}$ is found to be $3.88 \mathrm{~mm}^{2} / \mathrm{s}$ as shown in fig.3.7. The ASTM standard stated that the viscosity of biodiesel must be between 1.9-6 $\mathrm{mm}^{2} / \mathrm{s}$.

The general comparison of the biodiesels produced in this experiment with international standards is illustrated in Table3.4. As it can be seen in table3.4, majority of the physicochemical properties of the fleshing oil biodiesel were in good agreement of the international standards.

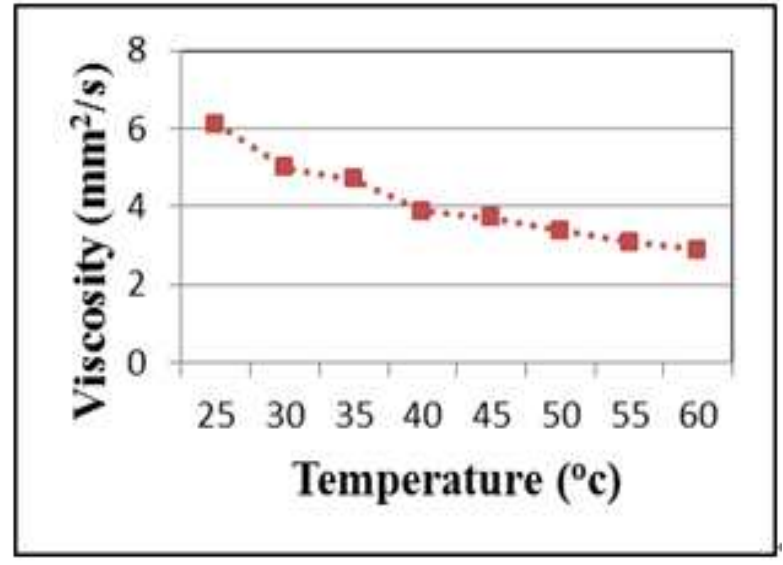

Figure9. Effect of Temperature on viscosity

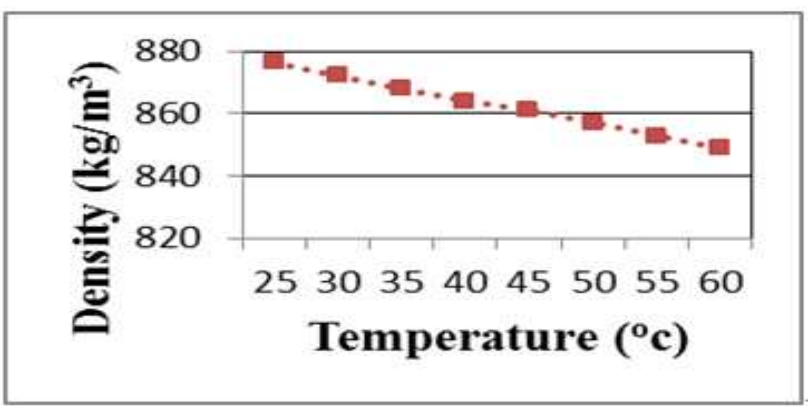

Figure 10.Effect of Temperature on Density 


\section{Comparison of the Fleshing Oil Biodiesel with ASTM and EN Standards}

The general comparison of the biodiesels produced in this experiment with international standards is illustrated in Table3.4. As it can be seen in table3.4, majority of the physicochemical properties of the fleshing oil biodiesel were in good agreement of the international standards.

Table 4. Comparison of experimental biodiesel with standards

\begin{tabular}{|c|c|c|c|c|c|}
\hline Property & Unit & EN-14214 & ASTM-D6751-10 & Diesel & Experimental Biodiesel \\
\hline Density@25 $\mathrm{c}$ & $\mathrm{Kg} / \mathrm{m}^{3}$ & $860-900$ & - & $840-860$ & 876.88 \\
\hline Kinematic viscosity@40 & $\mathrm{mm}^{2} / \mathrm{s}$ & $3.5-5.0$ & $1.9-6.0$ & $1.9-3.8$ & 3.88 \\
\hline Acid value & $\mathrm{mg} \mathrm{KOH} / \mathrm{g}$ & $0.5 \max$ & $0.5 \max$ & - & 0.45 \\
\hline HHV & $\mathrm{MJ} / \mathrm{kg}$ & - & - & $43.3-46.7$ & 40.73 \\
\hline Iodine value & $\mathrm{gI}_{2} / 100 \mathrm{~g}$ & $120 \max$ & - & - & 62.1 \\
\hline Cetane number & - & - & $46-70$ & $47-55$ & 61.25 \\
\hline
\end{tabular}

\section{Conclusions}

To screen out the optimal operating condition for the production of biodiesel from leather industry fleshing waste, three parameters that affect the production process has been studied. Several experiments were performed for a wide range of temperature, methanol-oil ratio and catalyst concentration. In this study, low cost fleshing waste as feed stock has been investigated experimentally for biodiesel production. A simple batch type oil extractive boiler was used to extract the fleshing oil at a temperature of $97^{\circ} \mathrm{C}$ and the oil was separated from the impurity by centrifuge. The resulting biodiesel was characterized for its physicochemical properties. The study shows that fleshing waste has an oil yield of $64 \%$ and FFA content of $12.33 \%$. Consequently, acid pretreatment experiment was conducted to reduce the FFA below $2.5 \%$ so as to minimize the saponification reaction. From the study, it was observed that methanol ratio of $30: 1$, sulfuric acid percentage of $10 \%(\mathrm{w} / \mathrm{w})$ and contact time of $1 \mathrm{hr}$ were sufficient to reduce FFA to $1.5 \%$ at $60^{\circ} \mathrm{C}$. The proximate transestrification reaction yield is $97 \%$ at optimum operating conditions. And also from the physicochemical property analysis, the produced biodiesel have a viscosity of $3.88 \mathrm{~mm}^{2} / \mathrm{s}$, HHV of $40.73 \mathrm{MJ} / \mathrm{kg}$, iodine value of $62.1 \mathrm{gI} 2 / 100 \mathrm{ml}$ and density of $876.88 \mathrm{Kg} / \mathrm{m}^{3}$.which are in the range of international standards.

Summarizing, fleshing leather industrial wastes was evaluated as a potential feed stock for biodiesel production in developing countries such as Ethiopia.

\section{Acknowledgement}

The research fund was granted from the research and community service of Bahir Dar University.

\section{References}

[1] LAY L. MYINT. Process analysis and optimization of biodiesel production from vegetable oils.

[2] Ratledge, Boulton CA. Fats and oils. In: Moo Young M., Blanch HN, Dream S, Wang DIC, editors, Comparative
Biotechnology in industry, agriculture and medicine, 1985 vol. 3. New York: Pergamon Press, p. 983-1003.

[3] Lee I, Johnson LA, Hammond EG. Use of branched-chain esters to reduce the crystallization temperature of Biodiesel. 1995, JAOCS; 72:1155-60.

[4] The Federal Environmental Protection Authority, Environmental impact Assessment Guideline for Tanneries

[5] Alptekin E et al. Evaluation of leather industry wastes as a feedstock for biodiesel production. Fuel (2011), doi: 10.1016/ j.fuel.2011.08.055.

[6] Kolomaznik K, Barinova M, Furst T. Possibility of using tannery waste for biodiesel production. JALCA 2009; $104: 177-82$.

[7] ASTM D 6751. ASTM's Standard Specification for Biodiesel Fuel (B100) Blend Stock for Distillate Fuels.

[8] Fukuda, H., A. Kondo, and H. Noda. 2001. "Biodiesel fuel production by transesterification of oils." J Biosci Bioeng. 92(5):405-416.

[9] Vivian Feddern et al., Embrapa Swine and Poultry, Brazil. Animal Fat Wastes for Biodiesel Production.

[10] Caye M. Drapcho, Nghiem Phu Nhuan and Terry H. Walker. Bio-fuels Engineering Process Technology.

[11] Andualem Ayalew. Cleaner Production Options for Solid Waste Management in the Leather Industry. Addis Ababa University.

[12] Schinas P. Karavalakis G. Davaris C, Anastopoulos G, Karonis D, Zannikos F, et al. Pumpkin (Cuccurbita pepo L) seed oil as an alternative feedstock for the production of biodiesel in Greece. Biomass Bioenerg 2009:33(1):44-9.

[13] Alhasan M, Isah AG and Garba MU (2005). Production and Characterization of Biodiesel from Cottonseed Oil. The 6th Annual Engineering Conference S.E.E.T. F.U.T. Minna, 2005.

[14] Cocks, L. V. and Vanrede, C. Laboratory Hand book for oil and Fat analysis. New York: Lawson press, 1984.

[15] Susan A. Roces, Raymond Tan, Francisco Jose T. Da Cruz, Shuren C. Gong, and Rison K. Veracruz. Methanolysis of Jatropha Oil Using Conventional Heating.

[16] Ananthakrishnan TN (1982). Bioresources Ecology, Volume 
2. Oxford \& IBH Publishing

Co. Pvt. Ltd.

[17] Drapcho, Caye, Nghiem Phu Nhuan and Terry H.Walker. Biofuels Engineering Process Technology. New York Chi

[18] Canakci, M., and J. Van Gerpen. 1999. "Biodiesel production via acid cataly-sis." Trans ASAE. 42:1203-1210. cago San Fr: The McGraw-Hill Companies, Inc, 2008.

[19] ASTM D 6751. ASTM's Standard Specification for
Biodiesel Fuel (B100) Blend Stock for Distillate Fuels.

[20] Isler A, Sundu S, Tuter M, Karaosmanoglu F. Transesterification reaction of the fat originated from solid waste of the leather industry. Waste Manag 2010; 30:2631-5.

[21] Colak S, Zengin G, Ozgunay H, Sari O, Sarıkahya H, Yuceer L. Utilisation of leather industry pre fleshings in biodiesel production. JALCA 2005; 100(3):137-41. 